\title{
Motor imagery and action observation: cognitive tools for rehabilitation
}

\author{
Th. Mulder ${ }^{1,2}$ \\ ${ }^{1}$ Royal Netherlands Academy of Arts and Sciences, Amsterdam, The Netherlands \\ ${ }^{2}$ Center for Human Movement Sciences, University Medical Center Groningen, University of Groningen, Groningen, The Netherlands
}

Received 25 December 2006; Accepted 2 May 2007; Published online 20 June 2007

(C) Springer-Verlag 2007

\begin{abstract}
Summary Rehabilitation, for a large part may be seen as a learning process where old skills have to be re-acquired and new ones have to be learned on the basis of practice. Active exercising creates a flow of sensory (afferent) information. It is known that motor recovery and motor learning have many aspects in common. Both are largely based on response-produced sensory information. In the present article it is asked whether active physical exercise is always necessary for creating this sensory flow. Numerous studies have indicated that motor imagery may result in the same plastic changes in the motor system as actual physical practice. Motor imagery is the mental execution of a movement without any overt movement or without any peripheral (muscle) activation. It has been shown that motor imagery leads to the activation of the same brain areas as actual movement. The present article discusses the role that motor imagery may play in neurological rehabilitation. Furthermore, it will be discussed to what extent the observation of a movement performed by another subject may play a similar role in learning. It is concluded that, although the clinical evidence is still meager, the use of motor imagery in neurological rehabilitation may be defended on theoretical grounds and on the basis of the results of experimental studies with healthy subjects.
\end{abstract}

Keywords: Motor imagery; movement observation; motor learning; rehabilitation

\section{Introduction}

Human motor behavior is characterized by an extreme flexibility. We can pick up a cup with the right hand, with the left hand while the arm is positioned in all sort of angles, we can even pick it up by using our feet as the main effector organs. We can walk forward, backward, we can jump, dance, run, shuffle and produce all sorts of silly walks. Without any problem we seem to be able to produce an almost infinite stream of movements in order to reach

Correspondence: Theo Mulder, The Royal Netherlands Academy of Arts and Sciences, Kloveniersburgwal 29, 1011 JV Amsterdam, The Netherlands e-mail: theo.mulder@bureau.knaw.nl goals in the environment. This is a crucial feature of the motor system which is based on the acquisition of generalized neural representations of the many ways in which the environment's (mechanical) properties affect the motor system (Gribble and Scott 2002). Functional connections between these representations (neural ensembles) create a distributed organization with extreme flexibility and storage capacity for movement aspects such as the mode of coordination of multi-joint actions, velocity and direction (Dobkin 2000). This organization is maintained by ongoing use.

For a large part motor behavior can be seen as problem solving (Latash et al. 2002; Mulder and Geurts 1993; Mulder and Hochstenbach 2003; Wolpert et al. 2001). Indeed, we are continuously forced to find solutions for problems that appear in the environment. These solutions, however, can not be static but should always be tailored to the actual requirements. Indeed, when the environmental constraints are never the same, the solutions can also never be the same. This is an important point since it indicates that motor control can not be the result of a rigid hierarchically organized system, generating efferent commands to individual muscles and joints on basis of motor programs stored in a neural warehouse. Motor control is a much more heterarchical process based on the continuous interaction of motor processes with cognitive and perceptual processes (Rosenbaum 1991; Grush 2004; Schmidt and Lee 2005; Decety and Grèzes 2006).

The present article is focused on a specific aspect of this interaction. It is questioned whether movement imagination and action observation as cognitive-perceptual acts may play a role in re-learning motor skills. However, before 
we address the topics of motor imagery and observation in more detail, some remarks have to be made on the plasticity of the motor system.

\section{Cortical plasticity}

Cortical representations in the adult brain are not fixed or rigid but highly dynamic (Sanes et al. 1988; Salmon and Butters 1995; Buonomano and Merzenich 1998; Kolb and Whishaw 1998; Spitzer 1999; Rossini et al. 2003; Lledo et al. 2006). Local cortical connections and responses are continuously reorganized as a result of peripheral and central alterations of input. In other words, experience can modify brain structure. This ability of sensory and motor cortices to dynamically reorganize is an important component of normal learning and recovery after neural injury.

In a landmark experiment Merzenich et al. (1983) showed that if a body part becomes less active, (e.g. deafferentation), so that less (or no) response-produced afferent information is sent to the brain, its topographical representation in the somatosensory cortex decreases in size. These results have been replicated in numerous studies (see Allard et al. 1991; Benedetti 1991; Brasil-Neto et al. 1992; Merzenich and Jenkins 1993).

This cortical reorganization is not only the result of longterm structural lesions, but takes place also after relative short periods of lack of normal input, such as following a temporary ischaemic nerve block (Edeline et al. 1993; Brasil-Neto et al. 1993) or after a (relatively short) period of disuse (De Jong et al. 2003; Zanette et al. 2004).

In a recent study of Fiori et al. (2006) it was shown that subjects with focal hand dystonia (writer's cramp) were less able to mentally rotate the pictures of hands in order to give a laterality judgment. This is an interesting finding, since it has been indicated that mental rotation of body parts activates more or less the same brain structures as needed for the actual execution of movements with that body part. This indicates that the effects of pain and disuse are not limited to the peripheral effectors but lead to a central reorganization. In other words, pain influences the neural representation of a movement. Also other authors found a substantial central reorganization in both the somatosensory and the motor system as a result of neuropathic and musculoskeletal pain. In patients with chronic low back pain and fibromyalgia the amount of reorganizational change increases with the duration of the pain. In phantom limb pain and other neuropathic pain syndromes cortical reorganization is related to the intensity of the pain (Flor 2003).
Central reorganization, however, takes place not only as a result of deprivation of sensory input but also as a result of an increase of sensory input. For example Classen et al. (1998) were able to show that a training period of 15-30 min was sufficient to initiate a change of the TMS-evoked movement direction (Classen et al. 1998). More recently Liu and Ionnides (2005) trained healthy adults to detect small changes in the frequency of $21 \mathrm{~Hz}$ electrical stimulation applied to digits $2+3+4$ of the right hand for 4 hours. Before and after the training, magneto-encephalographic (MEG) signals were recorded using a whole-head MEG system. Increased activation was measured in the left primary somatosensory (L-SI) and medial parietal precuneus $(\mathrm{PCu})$ areas. Gaser and Schlaug (2003) showed that extensive musical training resulted in multi-regional changes in the brain (gray matter volume). Even simple movements, repeated over a short period of time, are effective in inducing cortical representational changes (Classen et al. 1998; Van Mier et al. 1998).

Nelles et al. (2001) showed that in patients with severe hemiparesis changes in regional cerebral bloodflow took place as a result of task-oriented arm training.

A number of studies revealed that altering sensory input in normal subjects distorts the perceived shape, size and orientation of the body (see Lackner 1988). Experimental manipulation of sensory input so that touch and vision are disconnected results in the 'rubber-hand' illusion, in which individuals misattribute tactile sensations felt by their hand to a rubber prosthetic hand that they see being stimulated. (Botvinick and Cohen 1998).

Activity-dependent plasticity takes place not only in the brain but also in the spinal cord. Recently Wolpaw and Tennissen (2001) stressed the importance of the spinal cord for motor learning and they described how spinal plasticity is shaped by sensory input.

Hence, the availability of multimodal response-related input forms a crucial factor for the intactness of motor representations in the brain, for the intactness of body awareness and also for learning and recovery. Against this background, learning can be seen as input-dependent plasticity that is reflected in changes in the brain.

Traditionally 5 sources of response-related input have been distinguished in relation to motor learning: 1) proprioceptive information, 2) tactile information, 3) vestibular information, 4) visual information and 5) (to a lesser extent) auditory information (see also Magill 1998; Mulder and Hochstenbach 2003; Schmidt and Lee 2005). All these 5 sources are directly related to the actual execution of movements. 
In the present article I will ask whether for motor learning it is always necessary to actually execute the movement. It is questioned whether it is possible to learn a movement not by executing it but by imagining the movement or by observing the movement as performed by others? In other words, does the imagination (and/or observation) of a movement result in a flow of information that is similar to the flow that is generated by the actual execution of a movement? I will show that there is ample evidence that motor imagery (and action observation) may, indeed, play a relevant role in the (re-)learning of motor skills. Answering this question is not only theoretically interesting in that it underscores the intricate relationship between cognitive processes and motor processes, but also clinically relevant. The clinical relevance is clear: in conditions where patients are not able (due to pain and/or a lesion) or not allowed to move (e.g. after tendon repair) they can "exercise" mentally in order to prevent the above mentioned representational changes that take place as a result of inactivity and disuse. Furthermore, in rehabilitation it may play a role as an additional tool for (motor) learning.

\section{Motor imagery}

We are able to imagine almost everything. Sitting at my desk and overlooking a canal in down-town Amsterdam, I can at the same time easily imagine that I walk outside the city on a country road. I can imagine scenes or objects that are not there, or no longer there. I can mentally perform actions which I can not perform in reality. I can imagine myself as a perfect dancer although reality has learned me that my motor networks are very reluctant to learn the repetitive and rhythmic motor patterns needed for that type of skill. Although this imaginative power can be used in the visual, auditory, and tactile domains, in the present text I will focus solely on the imagination of movements (motor imagery).

Motor imagery is a cognitive process in which a subject imagines that he/she performs a movement without actually performing the movement and without even tensing the muscles. It is a dynamic state during which the representation of a specific motor action is internally activated without any motor output. In other words motor imagery requires the conscious activation of brain regions that are also involved in movement preparation and execution, accompanied by a voluntary inhibition of the actual movement (Lotze and Cohen 2006).

A fast-growing number of studies indicated that brain areas engaged in the actual performance of movements are also active during motor imagery (Hallett et al. 1994;
Sirigu et al. 1995; Stephan et al. 1995; Lotze et al. 1999; Gerardin et al. 2000; Grezes and Decety 2001; Jeannerod 2001; Kimberley et al. 2006). Multiple studies showed the involvement of the premotor, supplementary motor, cingulate and parietal cortical areas, the basal ganglia, and the cerebellum, not only during the actual execution of a movement but also during the imagination of a movement (Hanakawa et al. 2003; Dechent et al. 2004).

Stippich et al. (2002) showed that the imagination of different moving body parts (foot, hand and tongue) activated the precentral gyrus in a somatotopic manner. Similar results were obtained by Ehrsson et al. (2003) who showed that imagery of finger, tongue and toe movements activated the somatotopically organized areas of the primary motor cortex in a systematic manner, which means that imagery of finger movement activated the finger area, imagery of toe movements activated the foot zones of the posterior part of the contralateral supplementary motor area and the contralateral primary motor cortex and imagery of tongue movements activated the tongue region of the primary motor cortex. These data suggest that the imagined body part is reflected more or less directly in the pattern of cortical activation. The results are in accordance with an earlier study by Fadiga et al. (1999) who demonstrated that motor imagery influenced the corticospinal excitability in a very specific way. For example, motor imagery of forearm flexion enhances the MEPs of the $\mathrm{m}$. biceps brachialis, an agonist during forearm flexion, whereas this was not the case during imagery of forearm extension, where the $\mathrm{m}$. biceps brachialis acts as an antagonist. Hence, motor imagery does not lead to a generalized muscular arousal but to movement-specific central activation patterns.

Some studies using fMRI also found activation in the primary motor cortex (Porro et al. 1996, 2000; Roth et al. 1996; Gerarding et al. 2000, see also Sharma et al. 2006). In a recent study Spiegler et al. (2004) showed bilateral activity in the primary motor cortex during motor imagery of tongue protrusion. However, primary motor cortex activity was found absent in other studies (Parsons et al. 1995; Hanakawa et al. 2003; Meister et al. 2004; De Lange et al. 2005) so that the degree of involvement of the primary motor cortex still is a matter of debate (see also De Vries and Mulder 2007).

In a recent study Stinear et al. (2006) showed that kinesthetic but not visual motor imagery modulated corticomotor excitability, particularly at the supraspinal level. This outcome is interesting since it indicates that not only the area but also the degree of activation depends on the type of imagery being performed. Furthermore, this finding is relevant for the clinical use of motor imagery. Indeed, motor 
imagery strategies can be divided into kinesthetic motor imagery and visual motor imagery. During kinesthetic motor imagery the subject has the feeling that he/she actually performs the movement with all the sensory consequences (first person perspective). During visual motor imagery the subject sees him/her self performing the movement as from a distance (third person perspective). The results of Stinear suggest that kinesthetic motor imagery would be more effective for motor learning than visual motor imagery. Also Ruby and Decety (2003) studied these two types of imagination. They trained individuals to imagine a series of actions as being performed either by themselves (first person perspective) or by another individual (third person perspective). Both perspectives were associated by the activation of common neural networks in the SMA, the precentral gyrus and the precuneus. First perspective taking, however, was associated with the increased activity in the left inferior parietal lobule and the left somatosensory cortex, whereas the third person perspective activated the right inferior parietal lobule, the posterior cingulate and the fronto-polar cortex.

This distinction between first person and third person perspective, has been described elsewhere as a distinction between internal imagery and external imagery (Magill 1998). In internal imagery the subject approximates a real life situation in such a way that the person actually experiences the sensory sensations that might be expected in that situation. During external imagery, the subject views him/her self as observing another person performing the movement.

Meister et al. (2004) studied musicians who played the piano "in the mind". When the pianists played music on a silent keybord, they activated a network consisting of the left primary sensorimotor area, the left cerebellum, the premotor/supplementary motor areas, the intraparietal sulci and the bilateral extrastriate visual areas. The pure imagination of the music performance activated the same network with the exception of the primary sensorimotor area in the left hemisphere and the right cerebellum.

$\mathrm{Li}$ et al. (2004) showed that motor imagery even had an affect on the spinal segmental excitability. Nine healthy adult participants had to perform a series of imagined flexion-extension movements of the fingers. The results indicated a subthreshold activation of spinal motoneurons.

Hence, at this moment there is ample evidence that motor execution and motor imagery activate overlapping areas in the brain. Although the majority of the studies are focused on hand/finger or mouth movements, it is in the context of the present text, relevant to note that the activation of brain cortical areas during motor imagery is not limited to hand/finger or mouth movements but that also the imagination of gross movements results in the activation of relevant areas. Malouin et al. (2003) reported the activation of the pre-supplemary motor area and the primary motor cortex during imagery of locomotor movements.

Besides the overlap in neural activation between imagery and execution there are also similarities in the behavioral domain. For instance, the time to complete an imagined movement is known to be similar to the time needed for actual execution of that movement. This phenomenon is known as mental isochrony. Parsons (2001) showed that the time needed to judge whether a rotated picture of a hand represents a left or a right hand is related to the degree of rotation of that picture. Furthermore, he showed that when the exposed hand positions were awkward or biomechanically difficult, the imagined rotation time increased more than for equally rotated hands in biomechanically easy positions and that the rotation time was similar to real hand rotation time for these positions. The fact that motor imagery seems to respect the normal biomechanical constraints of real movements indicates that these tasks are not accomplished by mere visual imagery, but must be solved by imagining the movement of one's own arm and hand.

Decety et al. (1993) studied subjects who where instructed to either actually perform or mentally simulate a leg exercise. Heart rate and respiration rate were measured in both conditions. The results showed that not only during actual exercise the heart rate and respiration rate began to increase but also in the mental condition where no work at all was produced.

These findings have led to a theoretical position termed the simulation hypothesis (Jeannerod 2001). This hypothesis states that movement execution, motor imagery and action observation are all driven by the same basic mechanism. Motor imagery and action observation are conceived as "offline" operations of the motor areas in the brain.

Also Naito et al. (2002) stressed the aspect of central simulation. They argued that motor imagery contains elements of kinesthetic sensations which may be seen as a substitute for the sensory feedback that would arise when the movement would be executed. They argued further that during motor imagery subjects internally simulate kinesthetic sensations associated with the imagined movement (see also Currie and Ravenscroft 1997 who discuss the simulation aspect from a more philosophical standpoint).

Together all these data show an important point, viz. that a cognitive activity, such as motor imagery is not a modality-free and symbolic act but an act that is embodied in that it activates sensory-motor areas in the brain. Thus, 
in the brain, imagination is not separate from action and perception (see also Jeannerod 1994).

\section{Observation}

Similar phenomena have been found for the observation of movements. Also here rCBF increases have been found in the premotor cortex, middle temporal gyrus, inferior and middle frontal gyri and parietal cortex during the perception of goal-directed hand movements (Gallese et al. 1996; Gallese and Goldman 1998; Grezes and Decety 2001). Maeda et al. (2002), not only showed how corticospinal excitability increased during the observation of hand movements, but also that the facilitation was larger during observation of natural hand-orientations than during the observation of unnatural hand orientations. The latter is in line with recent findings of Pelphrey et al. (2003) who reported that the observation of biological motion (a walking human) activated the superior temporal sulcus significantly more than the observation of non-biological motion (movements of isolated limb segments in space).

Brass et al. (2000) studied to what extent the observation of a movement influenced the execution of that movement. The authors used a reaction time paradigm. Subjects were instructed to perform a finger movement as fast as possible. The results indicated that the initiation times of the movements were faster when the movement that had to be performed was identical to the movement that was observed. For example, when a subject observed a model performing a finger-lifting movement with hand palm down, the initiation time of the execution of an identical movement was significantly shorter than the initiation time of a fingerlifting movement with the hand-palm up. These results provided evidence for the influence of observation on movement execution. Similar results were obtained by Urgesi et al. (2006) who also investigated the influence of the posture of the observer's hand and that of the model's hand on the facilitation of potentials recorded from the muscles of the hand during the observation of finger movements. The main question was whether the activation of a muscle is related to its functional role in the observed movement or to the congruency between the posture of the observed hand and the hand of the observer. The results showed a facilitation of the FDI muscle only during the observation of index finger movements that, if actually performed, would imply the involvement of that muscle. The finding that motor facilitation takes place only during observation of movements that map the motor function of the recorded muscles is in line with the notion that observed movements are directly matched onto the observer's motor system.
Mattar and Gribble (2005) showed that observing another person undergoing a process of motor learning influenced the performance of the observer. Subjects were observing a video depicting another person learning a clockwise force field. These subjects performed significantly better when later tested than control subjects who did not observe the movement pattern. Hence, by observing another individual's attempts to move accurately in a novel force environment, the observer was able to form a neural representation of the environment's mechanical properties, which could be used for the performance of that movement.

Magnee et al. (2007) investigated whether the observation of emotional facial expressions would lead to the imitation of these expressions by the observer. They asked whether this imitative reaction was driven by automatic mimicry or that it was the result of the recognition of the observed emotion. Their results seem to indicate that spontaneous facial imitation is more related to an emotional reaction than to facial mimicry.

The mirror neuron system plays a central role in these findings (see Rizzolatti 2005). Mirror neurons fire not only when a monkey (or a human) performs a movement, but also when someone else executes that movement and the subject is observing the performance. Fadiga et al. (1995) provided in a TMS study the first evidence for the existence of a mirror system in humans by showing that the observation of a movement resulted in motor facilitation.

Although mirror neurons first were solely described for hand movements (grasping), recently it has been described that mirror neurons also fire during the execution of mouth movements. In a brain imaging study of Buccino et al. (2004) in which human subjects were instructed to observe mouth actions performed by humans (silent speech), monkeys (lip smacking) and dogs (barking) it was shown that the observation of human silent speech activated the pars opercularis of the left inferior frontal gyrus, the premotor section of Broca's region. The observation of monkey lip smacking activated the same region but to a smaller extent, whereas the observation of the barking dog only activated the extrastriate visual areas. Probably barking is too far away from the sensorimotor representations we have related to mouth action. Also Watkins et al. (2003) showed that the observation of communicative, speech-related mouth movements, facilitated the excitability of the motor system involved in the production of these movements. Hence, action observation automatically triggers action simulation and by this action observation facilitates action execution (Jeannerod 2001; Gallese 2005).

An interesting characteristic of the mirror neurons is that, during action observation, mirror neurons only discharge 
when a biological effector (a hand) interacts with an object, and not when the action is performed by using a tool (see also Di Pelegrino et al. 1992; Gallese et al. 1996; Tai et al. 2004). The neurons remain silent also when the grasping movement is performed in vacuo, that is, without an object. This was reflected in an fMRI study by Buccino et al. (2001). During the scanning session the subjects were asked to observe object-related and non-object-related movements performed by another individual with different body parts (arm, hand, mouth and foot). The following actions had to be observed: biting an apple and chewing (mouth actions), reaching and grasping a ball or a little cup and mimicking these actions without the objects (hand actions), kicking a ball or pushing a brake or mimicking these actions without the target objects (foot actions). The results showed that when a subject observed actions performed by another person with different effectors, different parts of the pre-motor cortex were activated. During the observation of mouth actions there was a bilateral activation of ventral area 6 and area 44, plus an activation of right area 45. During hand actions, a more dorsal part of ventral area 6 , plus a dorsal sector of area 44 were activated in both hemispheres. The observation of foot actions activated the dorsal sector of area 6 bilaterally (Buccino et al. 2001, pp 403). These results are important since they showed that the effector-related somatotopic activation pattern exists not only during the execution and imagination of a movement but also during the observation of a movement. Furthermore, the data revealed a marked difference between activation patterns in object-related actions and non-object related actions. In the latter case the activation was much lower or even absent.

\section{Motor learning by means of motor imagery and observation}

As argued before, movement execution, motor imagery and action observation are all driven by the same basic mechanism. Motor imagery and action observation are conceived as offline operations of the motor system.

Both motor imagery and movement observation may play a role in (re-)learning motor control. However, until now controlled group-studies on the clinical effect of motor imagery are rare.

On the basis of the reviewed experimental studies it can be argued that also observation may facilitate the motor system. Observation can be seen as a sort of motor priming which has clinical significance. Indeed, the observation of a movement (or action) may facilitate the execution of that movement. The above mentioned results of Brass et al.
(2000) and Urgesi et al. (2006), indeed, provide some evidence for this argument. However, until now no clinical studies exist in which this argument has been tested in a patient-related context.

In sports and other physical activities the learning effects of motor imagery (mental practice) are more extensively documented. A number of older studies showed that motor imagery enhanced physical proficiency (Vandell et al. 1943; Clark 1960; Corbin 1972; Noel 1980). Vandell et al. (1943) showed that groups of subjects who mentally trained basketball free throws demonstrated an improved skillfulness that was similar to those who physically practiced the task. Clark (1960) was able to show that when motor imagery was substituted for physical practice, the motor imagery group performed almost as good as the group that has physically exercised, and that a combination of physical exercise and motor imagery was superior for motor skill learning. Furthermore, it has been shown that repeated motor imagery, in particular imagery from the first person perspective, facilitates the learning of movements (Feltz and Landers 1983; Driskell et al. 1994). In a more recent study of Cumming and Hall (2000) with 159 athletes it was shown that motor imagery was a useful tool for sports training, and that elite athletes used motor imagery more than recreational athletes. Zijdewind et al. (2003) showed that imagery training of lower leg muscles significantly increased voluntary torque production of the ankle plantarflexor muscles and that this improvement was not the result of a nonspecific general motivational effect.

However, positive effects of motor imagery training have been described also outside the sport domain. PascualLeone et al. (1995) showed that during 5 days of training of musical performance both motor imagery and motor execution resulted in an increase in performance although the motor execution group out-performed the motor imagery group. Interestingly, the motor imagery group demonstrated the same training effect as the motor execution group after only one additional execution session.

In an intriguing study Yue and Cole (1992) showed that muscular force increased following motor imagery training. They studied the maximal voluntary force production of the fifth digit of the metacarpophalangeal joint in healthy subjects after a training program of repetitive, maximal isometric muscle contractions and compared the results of these physical exercises with the results of a mental training program that did not involve the repetitive activation of muscles. The mean abduction force of the left (trained) digit increased $30 \%$ for the contraction group and $22 \%$ for the imagining group, whereas a control group showed no improvement. Hence, an increase in force was achieved 
without any actual repeated muscle activation. An important aspect was that muscular force increased although during motor imagery no EMG activity could be registered. Yue and Cole conclude therefore that the increase in muscle strength following mental training could not be the result of neural changes at the execution level, but had to be attributed to higher (central) levels of the motor system involved in planning and programming.

A similar result was obtained by Mulder et al. (2004) who showed that subjects were able to learn to abduct their big toe by means of motor imagery, without moving the other toes. In this experiment subjects were randomly assigned to a group where they had to train by means of motor imagery, to a group were they had to physically practice the outward movement of the toe or to a control group that did not practice at all. They showed that the motor imagery group and the physical practice group significantly improved the ability to abduct the toe, whereas the control group showed no improvement. However, the improvement for the motor imagery group was significant only in the subjects who already had some ability to perform the abduction movement and not in subjects who found it impossible to abduct the toe at the start of the experiment. This finding may indicate that a representation of a movement must exist for motor imagery training to be effective. If this is true then it would implicate that totally novel movements can not be learned by means of motor imagery. However, caution remains necessary since the learning period was very short and the target movement was a rather artificial one.

In line with the above mentioned findings of Yue and Cole (1993) also Mulder et al. (2004) found no EMG output during motor imagery. The muscle was silent. In another study of Mulder et al. (2005) subjects had to imagine effortful squat movements. EMG, heart-rate and respiration were measured and again the results showed that with the exception of respiration no significant peripheral activation could be measured during motor imagery. These results seem to indicate that the learning effects of motor imagery are not the result of peripheral lowthreshold activation of muscles but the result of a central mechanism.

Lacourse et al. (2004) further explored this central mechanism. They studied the improvement on a 2-button press sequential task in a physical practice group, a motor imagery group and a no-practice group. They found that the improvements of the physical practice group were accompanied by increased striatal and decreased cerebellar activation, while the improvement in the motor imagery group was accompanied by increased cerebellar, pre-motor and striatal activation. The fact that motor imagery activated cortical and cerebellar sensorimotor networks suggests that motor imagery might be an effective additional tool for rehabilitation.

Although a number of reports exist of experimental studies with healthy participants or of experiments using motor imagery in sports, controlled clinical group studies using motor imagery in rehabilitation are still scarce. In a recent paper, Sharma et al. (2006) discussed the value of motor imagery for stroke rehabilitation. They also stressed the fact that until now only few studies exist that investigated the clinical value of motor imagery in stroke. On theoretical grounds, however, motor imagery may represent an interesting novel approach for rehabilitation (see also Butler and Page 2006). Motor Imagery activates relevant motor areas in the brain, it can be employed when and where the trainee wants to use it and as often as he wants it. Furthermore, the movements can be imagined in any context that is relevant for the individual patient. The latter is not a trivial remark, since from the motor learning literature it is known that a certain level of equivalence must exist between the learning/training context and the context of application. This is termed the "law" of situational equivalence, (Magill 1997; Mulder and Hochstenbach 2003; Schmidt and Lee 2005).

The same is true for the therapeutic use of observation and imitation. We are not aware of any studies that use observation for rehabilitation. There is an ongoing study by Buccino et al. (2006) that shows some promising results of observation therapy in stroke rehabilitation. However, these results are preliminary and need to be confirmed when the study is completed. In the next section I will focus, therefore, primarily on the empirical findings that exist in relation to motor imagery.

\section{Motor imagery as a tool for motor rehabilitation}

In an older study of Fansler et al. (1985) 36 elderly women over the age of 70 were assigned to one of 3 conditions: Condition A, control; Condition B, relaxation; or Condition $\mathrm{C}$, ideokinetic facilitation. Baseline and final measures of one-legged balance time were compared after a 3-day intervention period. Results showed significant improvement between baseline and final measures within condition $\mathrm{C}$ only. The authors concluded that mental practice of a physical task can improve performance and may be of use to the clinician.

Also Linden et al. (1989) reported better equilibrium characteristics in elderly women as measured by walking balance and foot placement measures as a result of a combined treatment of motor imagery and physical therapy. 
Fairweather and Sideway (1993) were able to show that a 3-week imagery program combined with physical exercises, reduced back pain and improved postural control in patients who suffered from chronic back pain and were assessed as having varying degrees of lordosis and kyphosis.

Cincotta et al. (1999) used motor imagery in a case study with a locked-in patient. The patient was quadriplegic and mute, but she could blink and make vertical eye movements on command. One month after the stroke EMG and TMS recordings revealed no motor activity in the right abductor digiti minimi muscle. However, when the patient was instructed to think as lively as possible about the movement of the paralyzed little finger, the latency and elicitability of the responses improved as compared to the relaxation condition. Although no functional gains were reported, this result is not trivial since it indicates that motor imagery can be used for regaining some control over a peripheral effector, even in the case of a locked-in patient. This may open new possibilities for rehabilitation research in these patients. Indeed, it may be that motor imagery could be used for the control of external devices by using the output signal created by the imagination of a movement as the input signal for a machine. The work of Pfurtscheller (2006), that will be mentioned at the end of this section shows that this is not an unrealistic idea. (See also Hochberg et al. 2006, who showed that neuronal activity recorded through a 96-microelectrode array implanted in primary motor cortex related to the intended hand motion could be used for modulating cortical spiking patterns three years after spinal cord injury).

In a study with stroke patients Page (2000) tested the beneficial effect of motor imagery on arm function in stroke patients. Eight stroke patients with a hemiparetic right arm underwent a 4 week training program consisting of motor imagery and occupational therapy. The results of this program were compared to the results of 8 controls who received only occupational therapy. Arm function was assessed by means of the Fugl-Meyer scale. The results indicated that the stroke patients who received the combined program improved significantly more that those who received only occupational therapy. The patients in this study were all stroke patients in the early post stroke period, in that their post-stroke period ranged from 2-11 months.

It is an interesting question whether motor imagery would be clinically useful also for chronic stroke patients with a more stabilized motor status. This question was investigated in another study by Page et al. (2005). Six patients, at least 1 year post stroke were trained for 6 weeks with a treatment combination of physical therapy and motor imagery. The results of this group, in terms of functional improvements of the hemiparetic arm, were compared to the improvements of a control group that received physical therapy combined with relaxation exercises. The results indicated that arm function improved more for the group that received the combined treatment of physical therapy and motor imagery than for the group that received physical therapy combined with relaxation training which indicated that motor imagery may play a therapeutic role even in patients more than 1 year post stroke.

Liu et al. (2004) studied 26 stroke patients that received motor imagery in combination with physical therapy during 3 weeks, for $1 \mathrm{~h}$ a day. The authors were able to show that the patients in the motor imagery group improved significantly more on functional tasks than the patients in the control group who received only additional assistance from the therapist. However, their intervention protocol was not aimed at relearning basic motor skills but at the learning of movements for performing daily activities, such as folding the laundry. Therefore, specific instructions for forming a kinesthetic image or to use first person imagery were absent in this study. This suggests that these patients did not use "real" motor imagery but a form of visual imagery. This may explain why they showed a beneficial effect on the daily living tasks, but no effect on the motor performance per se. The patients in the motor imagery group did improve on neuropsychological tasks measuring attention, suggesting that their capacity in attentive processing had been improved as a result of the mental imagery training. This may indicate that visual imagery might be used for relearning the more cognitive and planning aspects of movements, whereas motor imagery could play a role in relearning basic motor skills. However, since this argument refers to just a single study, we have to be careful.

Cicinelli et al. (2006) employed transcranial magnetic stimulation (TMS) in a population of hemiparetic stroke patients in a post-acute stage to map out the abductor digiti minimi (ADM) muscle cortical representation of the affected $(\mathrm{AH})$ and unaffected $(\mathrm{UH})$ hemisphere at rest, during motor imagery and during voluntary contraction. Imagery induced an enhancement of the ADM map area and volume in both hemispheres in a way which partly corrected the abnormal asymmetry between $\mathrm{AH}$ and $\mathrm{UH}$ motor output seen in rest condition. Their findings demonstrated that motor imagery significantly enhanced the cortical excitability of the hemisphere affected by stroke in a post-acute stage.

In an innovative study Pfurtscheller et al. (2006) showed that it was possible for a subject to move through a virtual street without using any muscular activity, but by imagining feet movements. A brain-computer interface was used 
that transformed intention-related EEG signals into an output signal that could drive the events in the virtual environment. The imagination of the feet movements affected the sensorimotor EEG signals in such an extent that it could be used as a control signal.

As a conclusion it can be stated that it is still extremely difficult to draw any evidence-based conclusions regarding the use of motor imagery in rehabilitation (see also Braun et al. 2006; Sharma et al. 2006; De Vries and Mulder 2007). The majority of the studies, until now, can be characterized as clinical case studies or pre-experimental studies (Page et al. 2001; Yoo et al. 2001; Stevens and Stoykov 2003; Crosbie et al. 2004; Dickstein et al. 2004; Dijkerman et al. 2004; Jackson et al. 2004).

\section{Is every patient able to use motor imagery?}

This is a relevant question. Indeed, when brain damage has wiped out the capacity to imagine movements, motor imagery would be a senseless therapeutic innovation. Jackson et al. (2001) argued that lesions to the parietal lobes may impair motor imagery. Also Lotze and Halsband (2006) argued that patients with parietal lesions and with left lateral prefrontal lesions are not able to imagine a movement.

Sirigu et al. (1996) showed that patients with lesions of the parietal cortex were impaired in a mental isochrony task. They were not able to predict the time necessary to perform a finger movement task. They argued that the parietal cortex is important for generating mental representations of movements.

Yaguez et al. (1999) showed that disorders of the basal ganglia influenced the capacity to imagine movement execution. They compared the ability to learn a graphomotor task in 2 groups of neurological patients. The first group consisted of patients suffering from Parkinson's disease, whereas the second group consisted of patients with Huntington's disease. They compared the 2 groups after a 10 min motor imagery training period. The results were remarkable, it was found that motor imagery had a positive effect on the motor performance of Huntington patients but no effect on the performance of the Parkinson patients. Parkinson patients did not learn the graphomotor task with motor imagery but also not by actual physical exercise. Furthermore, the Parkinson patients were impaired in the use of visual imagery. The effect of visual imagery in the Huntington group was correlated with the degree of atrophy in the caudate nucleus which may indicate that atrophy of the caudate nucleus specifically affected visual imagery, without affecting motor imagery (see Jackson et al. 2001, p 1138).
In a PET study Thobois et al. (2000) showed that in Parkinson patients, brain activation during motor imagery was abnormal, compared to normal control subjects. They argued that these motor imagery abnormalities suggest that the physiological processes underlying motor imagery seem to be sensitive to dopaminergic dysfunction. In a way this is not unexpected because motor imagery reflects the activation of an internal action representation without any external guidance which is a difficult task for patients with Parkinson's disease.

By using EEG Lim et al. (2006) studied the effect of visual imagery and motor imagery on the Contingent Negative Variation (CNV) in Parkinson patients and in a group of age-matched controls. The $\mathrm{CNV}$ is a slow negative movement and sensory-related potential that reaches it maximal amplitude at the vertex. Two main components can be distinguished in the CNV, an early and a late component. The early component is frontally distributed and involves the prefrontal cortex and the cingulated motor areas. The late component is generated by the basal-gangliathalamocortical loop and reflects activity in the primary motor cortex. The authors investigated whether imagery would alter the movement related potentials for patients with Parkinson disease. It was expected that motor imagery would have a larger effect on the amplitudes of the CNV compared to visual imagery (Lim et al. 2006, p. 2309). The results indicated that $10 \mathrm{~min}$ of visual imagery had neither any effect on the amplitude (Global Field Power) of the late CNV in Parkinson patients nor on the amplitudes of the $\mathrm{CNV}$ in the controls. Motor imagery, however, increased the amplitude (global field power) of the late CNV in Parkinson patients but not in controls. These authors concluded, therefore, that motor imagery could be a promising method for motor rehabilitation in Parkinson patients. Hence, these results are partly in contrast to the earlier findings of Yaguez et al. (1999) and Thobois et al. (2000).

Earlier studies of brain injured hemiplegic subjects suggest that they may retain the ability to generate images of movements they no longer can perform. In general these results were based on introspection or on questionnaires. Johnson (2000) employed a more objective procedure to investigate the imagery ability of hemiplegic patients. The patients had to indicate what the most efficient handgrip was to perform an action. In order to solve this problem they had to mentally simulate the action (motor imagery). He found that almost no differences were found between hemiplegic patients and healthy controls in solving that motor task.

In a related study that is still running in our own lab. We use a modified Parson's task for investigating whether stroke patients are able to perform motor imagination tasks. 
On a screen a hand (or a foot) is presented in a particular angular position. The subject had to decide as fast as possible if the observed hand or foot was a left or right hand (or foot). This task is contrasted with a letter rotation task. The letter $\mathrm{R}$ is presented on a screen also in different angular positions. In this condition the subject had to decide whether the $\mathrm{R}$ was positioned in a normal or in a mirror fashion. It is known that by performing the hand (or foot) task motor areas in the brain are involved, whereas during the performance of the R-task mainly visual area's are activated. The scores on the hand/foot reaction times (decision times), therefore, reflect the ability to rotate the body parts "in the head" which is an act of imagination. The preliminary results show that about $50 \%$ of the hemiplegic patients are able to perform the task in the same way as normal controls do (De Vries et al. in prep) ${ }^{1}$.

Mulder et al. (2007) explored the relation between age and imagery capacity. Scores on the vividness of movement imagery questionnaire were obtained for 333 participants, divided in 3 age groups ( $<30 \mathrm{yrs} ; 30-64 \mathrm{yrs}$ and $>64 \mathrm{yrs}$ ). The results showed that elderly participants were slightly worse in motor imagery capacity than younger participants, particularly in relation to motor imagery from a first person (internal) perspective.

As a conclusion it can be stated that it is still too early to give research-based advises concerning the type of patients that would profit most from motor imagery.

\section{Theoretical notions on motor imagery}

As indicated, the empirical basis for the clinical implementation of motor imagery procedures is still small. It is therefore relevant to what extent the theoretical explanation of motor imagery give further clues for the clinical use of motor imagery.

Traditionally two theoretical notions have been distinguished, a peripheral one and a central one. The peripheral theory is termed the psychoneuromuscular theory. This theory is based on the observation that during imagery of a particular movement the same muscles are activated as during the actual execution of that movement (Driskell et al. 1994; Boschker 2001). Furthermore, it is suggested that the same neuromotor pathways that are involved in the execution of a specific action are activated also during mental practice. This activation helps skill learning by improving the appropriate coordination patterns as a result of the strengthening of motor programs in the motor cortex, and

\footnotetext{
${ }^{1}$ De Vries S, Tepper M and Mulder Th. (in prep) Are stroke patients able to imagine movements they can not perform?:
}

by priming the corresponding motoneurons of the muscles necessary to execute a motor task (Page et al. 2001).

The psychoneuromuscular theory is supported by a number of studies. Jacobson (1932) was one of the first to demonstrate an increase in muscular activity when subjects were imagining movements. This muscular activity would function as afferent sensory input to motor control centres in the brain. Also more recent studies showed an increase in electromyographic (EMG) activity during imagined action (Hale 1982; Wehner et al. 1984; Jowdy and Harris 1990; Weiss et al. 1994; Bakker et al. 1996; Livesay and Samras 1998).

However, at the same time, motor imagery experiments have been performed in which EMG activity or other peripheral activation were absent during movement imagery. Yue and Cole (1992) showed an improvement of force production after mental training without actual repeated muscle activation. The results of Mulder et al. $(2004,2005)$ also showed improvement without any peripheral activation. It can be argued, that if motor imagery, indeed, results in peripheral activation, we actually can not talk about motor imagery in the strictest sense, since the definition of motor imagery refers to the mental execution of a movement without any activation of the muscle(s). The obtained experimental results, therefore, are highly dependent on the instruction given to the participants.

At this moment more evidence exists for a central explanation of motor imagery. Especially Galese (2005) (Gallese and Lakoff 2005, but see also Jeannerod 2001) stressed that motor imagery may be seen as the internal simulation of actions. Grush (2004) takes a related standpoint, but goes one step further by stating that motor imagery results from the control centers of the brain driving an emulator of the body, whereby the normal efferent flow is disengaged from the muscle system. The emulator is a system that receives a copy of the efferent commands together with the estimated sensory consequences. Hence, when an efferent motor command is given, a correlary discharge is generated. This correlary discharge is sent to the emulator, so that it may update the motor representation. The crucial point is, that from the correlary discharge it is possible to predict the re-afference that will be generated by the movement when it will (would) be executed. This predicted afference is termed the efference copy.

The emulator concept is closely related to the concept of efference copy. The emulator mimics the input-output function of the sensorimotor system.

So, motor imagery creates an internal central flow of information that can be seen as a sensory estimation of the output (which does not takes place) and that can be used for 
learning. This mechanism explains also the above mentioned results of Mulder et al. (2004) who found that toe abduction could be learned by means of motor imagery, but only for the subjects who were already able to perform the target movement at least at a minimal level. Indeed, for totally novel movements it is in principle not possible to start the emulation cycle, since no representation of the action exists.

Although a detailed discussion about the background mechanisms of motor imagery exceeds the aim of the present paper, it can be argued that a solid theoretical basis exists for motor imagery as a cognitive phenomenon and that this basis justifies the exploration of motor imagery as a cognitive tool for rehabilitation.

\section{Final conclusions}

Motor imagery can be seen as a promising technique for motor rehabilitation. However, it is not a substitute for physical exercise it should be seen as a complementary but relevant technique to improve motor learning. At this moment it is difficult to draw any definitive conclusions regarding the clinical relevance. However, on the basis of the reported pilot and/or quasi-experimental studies and on the basis of modern motor control theory and learning theory, it can be argued that starting controlled clinical group-studies in order to investigate the value of motor imagery is more than justified.

\section{Acknowledgement}

This work has been supported by ZonMw, grant nr: 14350021 .

\section{References}

Allard TA, Clark SA, Jenkins WM, Merzenich MM (1991) Reorganization of somatosensory area $3 \mathrm{~B}$ representations in adult owl monkeys after digital syndactyly. J Neurophysiol 66: 1048-1058

Bakker FC, Boschker MSJ, Chung T (1996) Changes in muscular activity while imagining weight lifting using stimulus or response propositions. J Sport Exercise Psychol 18: 313-324

Benedetti F (1991) Recovery of tactile perception following the simulated amputation of one finger. Perception 20: 687-692

Boschker MSJ (2001) Action-based imagery: on the nature of mentally imagined motor actions. Free University Doctoral thesis, Amsterdam

Botvinick M, Cohen J (1998) Rubber hands "feel" touch that eyes see. Nature 391: 756

Buccino G, Binkofski F, Fink GR, Fadiga L, Fogassi L, Gallese V, Seitz RJ, Zilles K, Rizzolattii G, Freund HJ (2001) Action observation activates premotor and parietal areas in a somatotopic manner: an fMRI study. Eur J Neurosci 13: 400-404

Buccino G, Lui F, Canessa N, Patteri I, Lagravinese G, Benuzzi F, Poro CA, Rizzolati G (2004) Neural circuits involved in the recognition of actions performed by nonconspecifics: an fMRI study. J Cogn Neurosci 16: $114-126$
Buccino G, Solodkin A, Small SL (2006) Functions of the mirror neuron system: implications for neurorehabilitation. Cognit Behav Neurol 19: $55-63$

Buonomano D, Merzenich MM (1998) Cortical plasticity: from synapses to maps. Annu Rev Neurosci 21: 149-186

Butler AJ, Page SJ (2006) Mental practice with motor imagery: evidence for motor recovery and cortical reorganization after stroke. Archi Phys Med Rehabil 87 (Suppl 12) 2: 2-11

Braun SM, Beurskens AJ, Borm PJ, Schack T, Wade DT (2006) The effects of mental practice in stroke rehabilitaton: a systematic review. Arch Phys Med Rehabil 87: 842-852

Brasil-Neto JP, Cohen LG, Pascual-Leone A, Jabir FK, Wall RT, Hallett M (1992) Rapid reversible modulation of human motor outputs after transient deafferentation of the forearm: a study with transcranial magnetic stimulation. Neurology 42: 1302-1306

Brasil-Neto JP, Valls-Solé J, Pascual-Leone A, Cammarota A, Amassian VE, Cracco R, Maccabee P, Cracco J, Hallett M, Cohen LG (1993) Rapid modulation of human cortical motor outputs following ischaemic nerve block. Brain 116: 511-525

Brass M, Bekkering H, Wohlschlaeger A, Prinz W (2000) Compatibility between observed and executed finger movements: comparing symbolic, spatial and imitative cues. Brain Cogn 44: 124-143

Cicinelli P, Marconi B, Zaccagnini M, Pasqualetti P, Filipi MM, Rossini PM (2006) Imaged-induced cortical excitability changes in stroke: a transcranial magnetic stimulation study. Cerebral Cortex 16: $247-253$

Cincotta M, Tozzi F, Zaccara G, Borgheresi A, Lori A, Cosottini M, Cantello R (1999) Motor imagery in a locked in patient: evidence from transcranial magnetic stimulation. Ital J Neurol Sci 20: $37-41$

Clark LV (1960) Effect of mental practice on the development of a certain motor skill. Res Quart 31: 560-569

Classen J, Liepert J, Wise SP, Hallett M, Cohen LG (1998) Rapid plasticity of human cortical movement representation induced by practice. J Neurophysiol 79: 1117-1123

Corbin C (1972) Effects of mental practice on skill development after controlled practice. In: Morgan W (ed) Ergogenic aids and muscular performance. Academic Press, New York, pp 93-118

Crosbie JH, McDonough SM, Gilmore DH, Wiggam MI (2004) The adjunctive role of mental practice in the rehabilitation of the upper limb after hemiplegic stroke: a pilot study. Clin Rehabil 18: $60-68$

Cumming J, Hall C (2000) Deliberate imagery practice: the development of imagery skills in competitive athletes. J Sports Sci 20: 137-145

Currie G, Ravenscroft I (1997) Mental simulation and motor imagery. Philos Sci 64: 161-180

Decety J, Grèzes J (2006) The power of simulation: imagining one's own and others behavior. Brain Res 1079: 4-14

Decety J, Jeannerod M, Durozard D, Baverel G (1993) Central activation of autonomic effectors during mental simulation of motor actions. J Physiol 461: 549-563

Dechent P, Merboldt KD, Frahm J (2004) Is the human primary motor cortex involved in motor imagery? Cogn Brain Res 19: 138-144

De Jong BM, Coert JH, Stenekes MW, Leenders KL, Paans AMJ, Nicolai JPA (2004) Cerebral reorganisation of human hand movement following dynamic immobilisation. Neuroreport 14: 1693-1696

De Lange FP, Hagoort P, Toni I (2005) Neural topography and content of movement representations. J Cogn Neurosci 17: 97-112

De Vries SJ, Mulder Th (2007) Motor imagery and Stroke Rehabilitation: a critical discussion. J Rehabil Sci 39: 5-13

Dickstein R, Dunsky A, Marcovitz E (2004) Motor imagery for gait rehabilitation in post-stroke hemiparesis. Phys Ther 84: 1167-1177

Dijkerman HC, Ietswaart M, Johnston M, MacWalter RS (2004) Does motor imagery training improve hand function in chronic stroke patients? A pilot study. Clin Rehabil 18: 538-549 
Di Pellegrino G, Fadiga L, Fogassi L, Gallese V, Rizzolatti G (1992) Understanding motor events: a neurophysiological study. Experimental. Brain Res 91: 176-180

Driskell JE, Copper C, Moran A (1994) Does mental practice enhance performance? J Sport Psychol 79: 481-492

Edeline JM, Pham P, Weinberger NM (1993) Rapid development of learning induced receptive field plasticity in the auditory cortex. Behav Neurosci 107: 539-551

Ehrsson H, Geyer S, Naito E (2003) Imagery of voluntary movement of fingers, toes, and tongue activates corresponding bodypart specific motor representations. J Neurophysiol 90: 3304-3316

Fadiga L, Buccino G, Craighero L, Fogassi L, Gallese V, Pavesi G (1999) Corticospinal excitability is specifically modulated by motor imagery: a magnetic stimulation study. Neuropsychologia 37: 147-158

Fadiga L, Fogassi L, Pavesi G, Rizzilatti G (1995) Motor facilitation during action observation: a magnetic stimulation study. J Neurophysiol 73: 492-502

Fairweather MM, Sidaway B (1993) Ideokinetic imagery as a postural development technique. Res Quart Exercise Sport 64: 385-392

Fansler CL, Poff CL, Shepard KF (1985) Effects of mental practice on balance in elderly women. Phys Ther 65: 1332-1338

Feltz DL, Landers DM (1983) The effects of mental practice on motor skill learning and performance: a meta-analysis. J Sport Psychol 5: 25-57

Fiori M, Tinazzi M, Aglioti SM (2006) Selective impairment of hand mental rotation in patients with focal hand dystonia. Brain 129: 47-54

Flor H (2003) Cortical reorganisation and chronic pain: implications for rehabilitation. J Rehabil Med 35: 66-72

Gallese V (2005) Embodied simulation: from neurons to phenomenal experience. Phenomenol Cogn Sci 4: 23-48

Gallese V, Fadiga L, Fogassi L, Rizzolatti G (1996) Action recognition in the premotor cortex. Brain 119: 593-609

Gallese V, Goldman A (1998) Mirror neurons and the simulation theory of mind-reading. Trends Cogn Sci 12: 493-501

Gallese V, Lakoff G (2005) The Brain's concepts: the role of the sensorymotor system in conceptual knowledge. Cogn Neuropsychol 22: 455-479

Gaser C, Schlaug G (2003) Brain structures differ between musicians and non musicians. J Neurosci 23: 9240-9245

Gerardin E, Sirigu A, Lehericy S, Poline JB, Gaymard B, Marsault C (2000) Partially overlapping neural networks for real and imagined hand movements. Cereb Cortex 10: 1093-1104

Grezes J, Decety J (2001) Functional anatomy of execution, mental simulation, observation and verb generation of action: a meta-analysis. Hum Brain Mapp 12: 1-19

Gibble PL, Scott SH (2002) Overlap of internal models in motor cortex for mechanical loads during reaching. Nature 417: 938-941

Grush R (2004) The emulation theory of representation: motor control, imagery and perception. Behav Brain Sci 27: 377-442

Hale BD (1982) The effects of internal and external imagery on muscular and ocular concomitants. J Sport Exercise Psychol 4: 379-387

Hallett M, Fieldman J, Cohen LG, Sadato N, Pascual-Leone A (1994) Involvement of primary motor cortex in motor imagery and mental practice. Behav Brain Sci 17: 210

Hanakawa T, Immisch I, Toma K, Dimyan M, Van Gelderen P, Hallett M (2003) Functional properties of brain areas associated with motor execution and imagery. J Neurophysiol 89: 989-1002

Hochberg LR, Serruya MD, Friehs GM, Mukand JA, Saleh M, Caplan AC, Branner A, Chen D, Penn RD, Donoghue JP (2006) Neuronal ensemble control of prosthetic devices by a human with tetraplegia. Nature 442: $164-171$

Jacobson E (1932) Electrophysiology of mental activities. Am J Psychol 44: 677-694

Jackson PL, Doyon J, Richards CL, Malouin F (2004) The efficacy of combined physical and mental practice in the learning of a foot-sequence task after stroke: a case report. Neurorehabil Neural Repair 18: 106-111
Jackson PL, LaFleur MF, Malouin F, Richards C (2001) Potential role of mental practice using motor imagery in neurologic rehabilitation. Arch Physi Med Rehabil 82: 1133-1141

Jeannerod M (1994) The representing brain: neural correlates of motor intention and imagery. Behav Brain Sci 17: 187-245

Jeannerod M (2001) Neural simulation of action: a unifying mechanism for motor cognition. NeuroImage 14: 103-109

Johnson SH (2000) Imagining the impossible: intact motor representations in hemiplegics. Neuroreport 11: 729-732

Jowdy DP, Harris DV (1990) Muscular responses during mental imagery as a function of motor skill level. J Sport Exercise Psychol 12: 91-201

Kimberley TJ, Khandekar G, Skraba LL, Spencer JA, Van Gorp EA, Walker SR (2006) Neural substrates for motor imagery in severe hemiparesis. Neurorehabil Neural Repair 20: 268-277

Kolb B, Whishaw IQ (1998) Brain plasticity and behavior. Annu Rev Psychol 49: 43-64

Lackner JR (1988) Some proprioceptive influences on the perceptual representation of body shape and orientation. Brain 111: 281-297

Lacourse MG, Turner JA, Randolph-Orr E, Schandler SL, Cohen MJ (2004) Cerebral and cerebellar sensorimotor plasticity following motor imagery-based mental practice of a sequential movement. J Rehabil Res Devel 41: 505-524

Li S, Kamper DG, Stevens JA, Rymer WZ (2004) The effect of motor imagery on spinal segmental excitability. J Neurosci 24 : 9674-9680

Lim VK, Polych MA, Holländer A, Byblow WD, Kirk IJ, Hamm JP (2006) Kinesthetic but not visual imagery assists in normalizing the CNV in Parkinson's disease. Clin Neurophysiol 117: 2308-2314

Linden CA, Uhley JE, Smith D, Bush MA (1989) The effects of mental practice on walking balance in an elderly population. Occupat Ther $\mathbf{J}$ Res 9: 155-169

Liu KP, Chan CC, Lee TM, Hui-Chan CW (2004) Mental imagery for promoting relearning for people after stroke: a randomized controlled trial. Arch Phys Med Rehabil 85: 1403-1408

Liu L, Ionnides AA (2005) MEG study of short term plasticity following multiple digit frequency training in humans. Brain Topography 16: 239-243

Livesay JR, Samras MR (1998) Covert neuromuscular activity of the dominant forearm during visualization of a motor task. Percept Motor Skills 86: 371-374

Lledo PN, Alonso M, Grubb MS (2006) Adult neurogenesis and functional plasticity in neural circuits. Nature Rev Neurosci 7: 179-193

Lotze M, Cohen LG (2006) Volition and imagery in neurorehabilitation. Cogn Behav Neurol 19: 135-140

Lotze M, Halsband U (2006) Motor imagery. J Physiol 99: 386-395

Lotze M, Montoya P, Erb M, Hulsmann E, Flor H, Klose U (1999) Activation of cortical and cerebellar motor areas during executed and imagined hand movements: an fMRI study. J Cogn Neurosci 11: 491-501

Maeda F, Kleiner-Fisman G, Pascual-Leone A (2002) Motion facilitation while observing hand actions: specificity of the effect and role of observers orientation. J Neurophysiol 87: 1329-1335

Magill RA (1998) Motor learning: concepts and applications. McGraw Hill, New York

Magnee MJCM, Stekelenburg JJ, Kemner C, De Gelder B (2007) Similar facial electromyographic responses to faces, voices and body expressions. Neuroreport 18: 369-372

Malouin F, Richards C, Jackson PL, Dumas F, Doyon J (2003) Brain activation during motor imagery of locomotor related tasks: a PET study. Hum Brain Mapp 19: 47-62

Malouin F, Richards CL, Doyon J, Desrosiers J, Belleville S (2004) Training mobility tasks after stroke with combined mental and physical practice: a feasibility study. Neurorehabil Neural Repair 18: $66-75$ 
Mattar AG, Gribble PL (2005) Motor learning by observation. Neuron 46: $153-160$

Meister IG, Krings T, Foltys H, Boroojerdi B, Muller M, Topper R, Thron A (2004) Playing piano in the mind - an fMRI study on music imagery and performance in pianists. Cogn Brain Res 19: 219-228

Merzenich MM, Kaas JH, Wall J, Nelson RJ, Sur M, Felleman D (1983) Topographical reorganization of somatosensory cortical areas $3 \mathrm{~b}$ and 1 in adult monkeys following restricted deafferentation. Neuroscience 8 : $33-55$

Merzenich MM, Jenkins WM (1993) Reorganization of cortical representations of the hand following alterations of skin inputs induced by nerve injury, skin island transfers and experience. J Hand Ther 6 : 89-104

Mulder Th, Geurts ACH (1993) Recovery of motor skill following nervous system disorders: a behavioral emphasis. Bailliere's Clin Neurol 2: $1-13$

Mulder Th, Hochstenbach J (2003) Motor control and learning: implications for neurological rehabilitation. In: Greenwood RJ (ed) Handbook of neurological rehabilitation, Psychology Press, New York, pp 143-157

Mulder Th, Hochstenbach J, Van Heuvelen MJG, Den Otter AR (2007) Motor imagery: the relationship between age and imagery capacity. Hum Mov Sci 26: 203-211

Mulder Th, Zijlstra S, Zijlstra W, Hochstenbach J (2004) The role of motor imagery in learning a totally novel movement. Exper Brain Res 154: 211-217

Mulder Th, Zijlstra S, De Vries S (2005) Observation, imagination and execution of an effortful movement: more evidence for a central explanation of motor imagery. Exper Brain Res 163: 344-351

Naito E, Kochiyama T, Kitada R, Nakamura S, Matsumura M, Yonekura Y, Sadato N (2002) Internally simulated movement sensations during motor imagery activate cortical motor areas and the cerebellum. J Neurosci 22: 3683-3691

Nelles G, Jentzen W, Jueptner M, Müller S, Diener HC (2001) Arm training induced brain plasticity in stroke, studied with serial positron emission tomography. NeuroImage 13: 1146-1154

Noel R (1980) The effect of visuo-motor behavioural rehearsal on tennis performance. J Sport Psychol 2: 221-226

Page SJ (2000) Imagery improves upper extremity motor function in chronic stroke patients: a pilot study. Occup Ther J Res 20: 200-215

Page SJ, Levine P, Sisto SA, Johnston MV (2001) Mental practice combined with physical practice for upper-limb motor deficit in subacute stroke. Phys Ther 81: 1455-1462

Page SJ, Levine P, Leonard AC (2005) Effects of mental practice on affected limb use and function in chronic stroke. Arch Phys Med Rehabil 86: 399-402

Parsons LM (2001) Integrating cognitive psychology, neurology and neuroimaging. Acta Psychol 107: 155-181

Parsons LM, Fox PT, Downs JH, Glass T, Hirsch TB, Martin CC (1995) Use of implicit motor imagery for visual shape discrimination as revealed by PET. Nature 375 : $54-58$

Pascual-Leone A, Dang N, Cohen LG, Brasil-Neto J, Cammarota A, Hallett M (1995) Modulation of motor repsonse evokedby transcranial magnetic stimulation during the acquisition of new fine motor skills. J Neurophysiol 74: 1034-1045

Pelphrey KA, Mitchell TV, McKeown MJ, Goldstein J, Allison T, McCarthy G (2003) Brain activity evoked by the perception of human walking: controlling for meaningful coherent motion. J Neurosci 23: 6819-6825

Pfurtscheller G, Leeb R, Keinrath C, Friedman D, Neuper C, Guger C, Slater M (2006) Walking through thought. Brain Res 1071: 145-152

Porro CA, Cettolo V, Francescato MP, Baraldi P (2000) Ipsilateral involvement of primary motor cortex during motor imagery. Eur J Neurosci 12: $3059-3063$
Porro CA, Francescato MP, Cettolo V, Diamond ME, Baraldi P, Zuiani C (1996) Primary motor and sensory cortex activation during motor performance and motor imagery: a functional magnetic resonance imaging study. J Neurosci 16: 7688-7698

Rizzolatti G (2005) The mirror neuron system and imitation. In: Hurley $\mathrm{S}$, Chater $\mathrm{N}$ (eds) Perspectives on imitation: from cognitive neuroscience to social science. MIT Press, Cambridge, MA, pp. $55-77$

Rosenbaum DA (1991) Motor control. Academic Press, New York

Rossini PM, Caautti C, Pauri F, Baron JC (2003) Post-stroke plastic reorganisation in the brain. Lancet Neurol 2: 493-502

Roth M, Decety J, Raybaudi M, Massarelli R, Delon-Martin C, Segebarth C (1996) Possible involvement of primary motor cortex in mentally simulated movement: a functional magnetic resonance imaging study. Neuroreport 7: $1280-1284$

Ruby P, Decety J (2003) What you belief versus what you think they believe: a neuroimaging study of conceptual perspective taking. Eur $\mathrm{J}$ Neurosci 17: 2475-2480

Salmon DP, Butters N (1995) Neurobiology of skill and habit learning. Curr Opin Neurobiol 5: 184-190

Sanes JN, Suner S, Lanod JF, Donoghue JP (1988) Rapid reorganization of adult rat motor cortex somatic representation after motor nerve injury. Proc Natl Acad Sci USA 85: 2003-2007

Schmidt RA, Lee TD (2005) Motor control and learning: a behavioral approach. Human Kinetics Publ, Champaign

Shadmehr R, Mussa-Ivaldi FA (1994) Adaptive representation of dynamics during learning of a motor task. J Neurosci 14: 3208-3224

Sharma N, Pomeroy VM, Baron JC (2006) Motor imagery: a backdoor to the motor system after stroke? Stroke 37: 1941-1952

Sirigu A, Cohen L, Duhamel JR, Pillon B, Dubois B, Agid Y, PierrotDeseilligny C (1995) Congruent unilateral impairments for real and imagined hand movements. Neuroreport 6: 997-1001

Sirigu A, Duhamel JR, Cohen L, Pillon B, Dubois B, Agid Y (1996) The mental representation of hand movements after parietal cortex damage. Science 273: $1564-1568$

Spiegler A, Graimann B, Pfurtscheller G (2004) Phase coupling between different motor areas during tongue-movement imagery. Neurosci Lett 369: $50-54$

Spitzer M (1999) The Mind within the Net: models of learning, thinking and acting. MIT Press, Cambridge, Mass

Stephan KM, Fink GR, Passingham RE, Silbersweig D, Ceballos-Baum AO, Frith CD, Frackowiak RS (1995) Functional anatomy of the mental representation of upper extremity movements in healthy subjects. J Neurophysiol 73: 373-386

Stevens JA, Stoykov ME (2003) Using motor imagery in the rehabilitation of hemiparesis. Arch Phys Med Rehabil 84: 1090-1092

Stinear CM, Byblow WD, Steyvers M, Levin O, Swinnen SP (2006) Kinesthetic, but nog visual, motor imagery modulates corticomotor excitability. Exper Brain Res 168: 157-164

Stippich C, Ochmann H, Sartor K (2002) Somatotopic mapping of the primary sensorimotor cortex during motor imagery and motor execution by functional magnetic resonance imaging. Neurosci Lett 331: $50-54$

Tai YF, Scherfler C, Brooks DJ, Sawamoto N, Castiello U (2004) The human motor premotor cortex is "mirror" only for biological actions. Curr Biol 14: 117-120

Thobois S, Dominey PF, Decety J, Pollak P, Gregoire MC, Le Bars D, Broussolle E (2000) Motor imagery in normal subjects and in asymmetrical Parkinson's disease. Neurology 55: 996-1002

Urgesi C, Candidi M, Fabbro F, Romani M, Aglioti SM (2006) Motor facilitation during action observation: topographic mapping of the target muscle and influence of the onlooker's posture. Eur J Neurosci 23: $2522-2530$

Vandell RA, Davis R, Clugston HA (1943) The function of mental practice in the acquisition of motor skills. J Gen Psychol 29: 243-250 
Van Mier H, Tempel LW, Perlmutter JS, Raichle ME, Petersen SE (1998) Changes in brain activity during motor learning measured with PET: effects of hand of performance and practice. J Neurophysiol 80: 2177-2199

Watkins KE, Strafella AE, Paus T (2003) Seeing and hearing speech excites the motor system involved in speech production. Neuropsychologia 4 989-994

Wehner T, Vogt S, Stadler M (1984) Task-specific EMG characteristics during mental training. Psychol Res 46: 389-401

Weiss T, Hansen E, Beyer L et al. (1994) Activation during mental practice in stroke patients. Int J Psychophysiol 17: 91-100

Wolpaw JR, Tennissen AM (2001) Activity-dependent spinal cord plasticity in health and disease. Ann Rev Neurosci 24: 807-843

Wolpert DM, Ghahramani Z, Flanagan JR (2001) Perspectives and problems in motor learning. Trends Cogn Sci 5: 487-494
Yaguez L, Canavan AG, Lange HW, Homberg V (1999) Motor learning by imagery is differently affected in Parkinson's and Huntington's diseases. Behav Brain Res 102: 115-127

Yue G, Cole KJ (1992) Strength increases from the motor program: comparison of training with maximal voluntary and imagined muscle contractions. J Neurophysiol 67: 1114-1123

Yoo E, Park E, Chung B (2001) Mental practice effect on line-tracing accuracy in persons with hemiparetic stroke: a preliminary study. Arch Phys Med Rehabil 82: 1213-1218

Zanette G, Manganotti P, Fiaschi A, Tamburin S (2004) Modulation of motor cortex excitability after upper limb immobilization. Clin Neurophysiol 115: 1264-1275

Zijdewind I, Toering ST, Bessem B, Van der Laan O, Diercks RL (2003) Effects of imagery motor training on torque production of ankle plantar flexor muscles. Muscle Nerve 28: 168-173 